\title{
SPATIAL INHOMOGENE IN USA INNOVATION
}

\author{
Valerij N. Minat \\ Ryazan State Agrotechnological University named after P.A. Kostychev, Ryazan, Russian Federation
}

\begin{abstract}
The subject of this study is the spatially heterogeneous innovation activity carried out at the regional (meso) level of the United States, analyzed and evaluated on the basis of qualitative indicators (indicators and integral indicator) of the level of innovation potential and innovation activity of regional innovation systems that have received development and statistical accounting of the results of these activities in within specific states. The identified combinations, high correlation dependence and interconnection of indicators of the innovative potential and innovative activity of regional innovation systems of the US states, made it possible to substantiate a number of trends in the development of these systems, to assess the features of spatial integration and, at the same time, the different-level differentiation of these systems, reflecting the heterogeneity and uneven development innovation activity on the "centerperipheral" principle. The final typology of regional innovation systems of the US states, based on the logarithmically normal distribution of the indices of innovation activity and the integral indicator of the level of innovative potential of the average values for the period 2015-2019, results in a qualitative spatial diversity of these systems, determined by the joint influence of both economic phenomena on the deepening of heterogeneity and differentiation of the latter.

Key words: innovation activity, national innovation system of the USA, regional innovation system, innovation potential of the territory, integral indicator of the level of innovation potential, spatial differentiation.

Citation. Minat V.N. Spatial Inhomogene in USA Innovation. Vestnik Volgogradskogo gosudarstvennogo universiteta. Ekonomika [Journal of Volgograd State University. Economics], 2021, vol. 23, no. 2, pp. 149-160. (in Russian). DOI: https://doi.org/10.15688/ek.jvolsu.2021.2.13
\end{abstract}

УДК 339.972(73)

Дата поступления статьи: 10.02.2021

ББК 65.30 Дата принятия статьи: 25.02.2021

\section{ПРОСТРАНСТВЕННАЯ НЕОДНОРОДНОСТЬ ИННОВАЦИОННОЙ ДЕЯТЕЛЬНОСТИ США}

\author{
Валерий Николаевич Минат \\ Рязанский государственный агротехнологический университет им. П.А. Костычева, \\ г. Рязань, Российская Федерация
}

\begin{abstract}
Аннотация. Предметом исследования выступает пространственно неоднородная инновационная деятельность, осуществляемая на региональном уровне (мезоуровне) США, анализируемая и оцениваемая на основе качественных показателей (индикаторов и интегрального показателя) уровня инновационного потенциала и инновационной активности региональных инновационных систем, получивших развитие и статистический учет результатов указанной деятельности в рамках конкретных штатов. Выявленные сочетания, высокая корреляционная зависимость и взаимосвязь показателей инновационного потенциала и инновационной активности региональных инновационных систем штатов США позволили обосновать ряд тенденций развития указанных систем, дать оценку особенностям пространственной интеграции и в то же время разноуровневой дифференциации этих 종 систем, отражающей неоднородность и неравномерность развития инновационной деятельности по центр-перитерийному принципу. Итоговая типология региональных инновационных систем штатов США, выполненная на ๓ о основе логарифмически нормального распределения по индексам инновационной активности и интегральному ‡్ показателю уровня инновационного потенциала средних значений за период 2015-2019 гг., результирует качественное пространственное разнообразие указанных систем, определяемое совместным влиянием обоих экономических феноменов на углубление неоднородности и дифференциации последних.
\end{abstract}


Ключевые слова: инновационная деятельность, национальная инновационная система США, региональная инновационная система, инновационный потенциал территории, интегральный показатель уровня инновационного потенциала, пространственная дифференциация.

Цитирование. Минат В. Н. Пространственная неоднородность инновационной деятельности США // Вестник Волгоградского государственного университета. Экономика. -2021. - Т. 23, № 2. - С. 149-160. DOI: https://doi.org/10.15688/ek.jvolsu.2021.2.13

\section{Введение}

Инновационная деятельность, представляющая собой либо комплекс работ по созданию, освоению, распространению и использованию различных инноваций - в широком смысле, либо практическое использование интеллектуального потенциала при генерации инновационного продукта (в сочетании с материальным и энергетическим продуктом), обладающего новыми качествами, - в узком смысле, на государственном уровне осуществляется в рамках национальной инновационной системы (НИС). Последняя, в свою очередь, традиционно рассматривается как подсистема экономической системы страны. Концептуальные вопросы выбора оптимального пути инновационного развития (на макро-, мезо-, микроуровнях организационно-пространственной иерархии) и реализации модели НИС (на соответствующих уровнях) отличаются разнообразием предметной области исследования, соответствующей объекту определенного иерархического уровня. Функционирование и структурирование подсистем и элементов НИС, привязанных в своем развитии, размещении и взаимодействии к конкретной целостной территории, с позиций различных школ и направлений пространственной экономики (в рамках концепции инновационной среды) познается посредством такого научного конструкта (модели), как региональная инновационная система (РИС).

Считая обоснованным утверждение, что инновационная деятельность осуществляется на мезоэкономическом уровне в рамках многочисленных РИС - субнациональных пространственных единиц, именно этот феномен может быть, на наш взгляд, определен в качестве:

- во-первых, ключевого объекта в исследовании комплементарной (состоящей из дополняющих друг друга структур) инновационной деятельности страны, обладающей крупной и качественно неоднородной территорией и зна- чительной численностью населения, диверсифицированной экономикой знаний, инновационно ориентированной стратегией развития в условиях приближающейся, а по иному мнению - уже начавшейся, смены технологических укладов, возможностями эффективного использования региональных ресурсов: высококвалифицированных кадров, результатов НИОКР и т. д. в целостном инновационном процессе;

- во-вторых, динамического явления, связывающего в пространстве и времени макроуровневую систему - непосредственно НИС - с ее особенностями и масштабами, с одной стороны, и еще более многочисленные микроуровневые системы - отдельные агенты-новаторы и организации-новаторы (фирмы, компании, предприятия) - с другой стороны, в диалектическом единстве инновационного процесса, носящего как эволюционный, так и революционный характер.

Bсе перечисленные положения, на наш взгляд, отражены в формировании инновационной динамики Соединенных Штатов Америки - передовой по многим позициям страны современного мира, находящейся вместе с тем в «точке бифуркации» своего системно-исторического развития. Неопределенность самоорганизации социально-экономической системы США, имеющих федеративное внутригосударственное устройство, особенно остро выражается на региональном уровне общественных отношений. Таким образом, важное значение исследования опыта развития и функционирования американских РИС актуально теоретически и предопределено с практической точки зрения для формирования подходов к оценке регионального инновационного потенциала и анализа инновационной активности пространственно-территориальных образований других стран с аналогичной формой государственного устройства, в частности - Российской Федерации.

Современная инновационная деятельность РИС США, понимаемая как простран- 
ственно-временная категория, познаваемая в нашем конкретном случае на основе анализа показателей их инновационного потенциала и оценки результатов его использования, выраженной посредством инновационной активности, выступает предметной областью настоящего исследования. Выделяя РИС штатов в качестве объекта настоящего исследования, автор не забывает, что вышеупомянутые школы пространственной экономики отнюдь не постулируют развитие инноваций в рамках административных границ.

В настоящей работе выявление пространственных аспектов инновационной деятельности и характеристика соответствующих территориальных образований мезоуровня, статистически отраженные в границах соответствующих штатов, расположенных в рамках 9 субрегионов (статистико-экономических районов Бюро ценза США), состоящих из государственно-территориальных единиц - штатов, рассматривается нами в русле гипотезы о неоднородности и неравномерности экономики страны под влиянием (позитивном или негативном) процессов, вызванных этой дифференциацией. Указанное гипотетическое положение является теоретической и методологической базой исследования зависимости между уровнем инновационной активности и использования инновационного потенциала в рамках РИС штатов, субрегионов и страны в целом.

Цель настоящей работы - выявление тенденций пространственной неоднородности РИС штатов посредством анализа и оценки инновационного потенциала соответствующих территорий и инновационной активности как экономических свойств (факторов) конкретных РИС.

\section{Материалы и методы исследования}

В ряду многочисленных исследований, посвященных заявленной во введении проблематике, базовое положение автор отводит теоретико-методологическим работам, объектом исследования которых выступают конкретные и абстрактные инновационные пространственные системы, соответствующие так называемой североамериканской модели РИС [Бухарова, 2013; Лапаев, 2012; Porter et al., 2002]. Обзор представленных и многих других работ, результаты которых «преломлены» в аспекте исследования пространственной организации инновационной деятельности - региональной дифференциации в рамках единого инновационного пространства, позволяет вывить структурно-содержательную сущность основных категорий (применительно к предмету нашего исследования).

В частности, под РИС штата США мы будем понимать специфическую пространственную форму организации инновационной деятельности, являющуюся результатом реализации программы развития территории, включающей элементы инновационно-производственного «ядра», многофункциональной инфраструктуры и специфическую институциональную среду [Минат, 2020а]. Универсальными элементами данных РИС выступают: частно-государственное партнерство (ГЧП) в сфере венчурного бизнеса, региональные (территориальные) формы научно-производственной интеграции (НПИ), бизнес-инкубаторы, национальные и промышленные лаборатории, региональные инновационные кластеры (РИК) и др. При этом североамериканская модель РИС характеризуется определенным набором системно-структурных признаков: сложностью структуры и взаимосвязанностью элементов, наличием всех этапов инновационного процесса, активной и взаимодополняющей ролью бизнеса и органов власти, расширением предпринимательской деятельности вузов, открытостью для международного сотрудничества и др. Проведенные автором исследования показали, что вышеперечисленные элементы РИС и признаки существования последних в настоящее время определяют «лицо» инновационной экономики большинства штатов и субрегионов США [Минат, 2020б], не говоря уже о метрополитенских ареалах [Минат, 2020в], представленных сплошными урбанизированными территориями, где отмечается сверхконцентрация инновационной деятельности во всех ее проявлениях.

Каждый из взаимосвязанных элементов РИС в рамках субъектно-объектной структуры имеет свои функции, важнейшими из которых выступают функции по формированию и реализации инновационного потенциала (ИП), под которым автор, основываясь на опыте как российских [Антоненко, 2019; Зайков, 2019], 
так и американских [Abel, 2017] специалистов, понимает:

- в широком смысле - комплекс предпосылок, достаточных для перехода экономики, сконцентрированной на территории конкретного штата, субрегиона или США в целом, на новый качественный уровень развития;

- в узком смысле - возможность и способность РИС определенного пространственного уровня формировать и использовать инновационные ресурсы для осуществления полномасштабного инновационного процесса, peзультатом которого является конечный инновационный продукт.

В свою очередь, сформированный и накопленный ИП, как представляется автору, напрямую определяет инновационную активность (ИА) создаваемых и развивающихся (эволюционирующих) элементов конкретной РИС. Такая активность на региональном уровне воспринимается в качестве целенаправленной деятельности по освоению и использованию ИП, производству новшеств, созданию новых технологий, формированию условий и среды (в том числе правовой) инновационной деятельности, внедрению инноваций и т. д. [Carbelli, 2018]. Следовательно, категория ИА представляется более обширной, чем категория ИП, включая последнюю как свою первооснову, охватывая помимо инновационноресурсной базы производство (создание), реализацию и распределение инноваций в рамках региона и за его пределами.

Анализ и оценка представленных экономических феноменов применительно к РИС штатов США зависит как от подбора показателей и индикаторов, количественно и качественно характеризующих инновационную деятельность на региональном уровне, так и от выбора методических подходов к исследованию ИП и ИА в пространстве соответствующих РИС. Методологические и методические аспекты исследования ИП и ИА регионов нашли свое отражение в упомянутых выше исследованиях. Помимо них интересны обзорные работы, в которых авторы не только компилируют, но и критически оценивают имеющийся массив подходов к формированию системы показателей и непосредственно методике исследования ИП и ИА на региональном уровне [Баринова и др., 2017; Монахов, 2013].
Отмеченные труды стали базой для формирования методики настоящего исследования.

Сложность в выборе методических подходов как к непосредственно градации показателей, отраженных в официальной американской статистике, так и к анализу и оценке ИП и ИА РИС штатов США определяется прежде всего широким спектром («охватом») предмета исследования. Ставится задача не просто объединить статистико-экономические приемы и показатели, необходимые для анализа и оценки каждого из изучаемых феноменов (ИП и ИА) в рамках объекта исследования, но и доказательно увязать полученные результаты по каждому из них между собой. Выбранная методика позволяет обосновать взаимосвязь имеющегося, формируемого и реализуемого ИП с развитием ИА в рамках конкретных РИС штатов США, исходя из результатов направленной деятельности элементов этих РИС по использованию инновационных ресурсов.

Для выполнения поставленной задачи по формированию заявленной методики исследования автором использован следующий алгоритм действий.

Прежде всего, отметим, что американские исследователи уделяют большое внимание индексам и показателям, характеризующим преимущественно ИА в целом по стране, связанным, в частности, с рейтингованием регионов. Наиболее известными рейтингами регионального инновационного развития (РИР), применяемыми в США, являются: Portfolio Innovation Index, PI ${ }^{1}$ [Innovation ...]; State New Economy Index, SNEI ${ }^{2}$ [State New ...]. OTражает инновационную «емкость» территорий список штатов США по Американскому индексу человеческого развития - List of U.S. states by American Human Development Index, HDI ${ }^{3}$ [List of U.S. ...]. Для приведения к «общему знаменателю» всех имеющихся индексов вычисляется их среднее значение за период 2015-2019 годов.

Учет и использование указанных индексов можно считать первым шагом выбранного алгоритма действий, направленным на сбор и синтез уже готовых к анализу данных по ИА РИС штатов США, в числе которых выделяются блоки (группы) показателей, характеризующих ИП штатов. Индекс HDI преимуще- 
ственно отражает уровень развития человеческого капитала в интересующем нас разрезе - одного из важных элементов ИП, базиса ИА и инновационной деятельности в целом по каждому из штатов США.

Вторым шагом представляется необходимость проведения собственных расчетов интегрального показателя уровня ИП, используемого РИС штатов США, для последующей статистико-экономической оценки уровня этого потенциала в разрезе конкретных штатов. Для этого изначально определяется комплекс из 26 панельных данных (относительных и абсолютных показателей), рассчитанных как средняя величина за тот же 5-летний период времени с 2015 по 2019 г. и сгруппированных в разделы на основе:

- результатов инновационной деятельности (доля инновационных товаров, работ и услуг в общем объеме произведенных товаров, выполненных работ и предоставленных услуг экономикой штата, удельный вес инновационно-активных организаций и т. п.);

- затрат на осуществление инновационного процесса (затраты на НИОКР, затраты организаций-новаторов на технологические инновации);

- качества и количества человеческого капитала (численности специалистов высшей квалификации, занятых в НИОКР, показателей инновационной активности вузов США и др.);

- наличия институциональной структуры инновационного процесса и использования инновационно-внедренческой инфраструктуры (число / доля различных организационно-территориальных форм НПИ, РИК, ГЧП, национальных и промышленных лабораторий, вузов в инновационной деятельности, показатели информатизации и цифровизации инновационного процесса и т. п.).

Интегральный показатель уровня ИП штата США рассчитывается по следующей формуле:

$$
I P_{i}=\frac{\sum_{j=1}^{m} x_{i j}^{\prime}}{m}
$$

где $I P_{i}-$ интегральный показатель уровня ИП штата США; $x_{i j}^{\prime}$ - нормированное среднее за 2015-2019 гг. значение $j$-й характеристики $i$-го штата; $m$ - число характеристик.
Абсолютные показатели преобразуются в относительные величины и для устранения единиц измерения нормализуются по формуле:

$$
x_{i j}^{\prime}=\frac{x_{i j}-\min _{i} x_{i j}}{\max _{i} x_{i j}-\min _{i} x_{i j}},
$$

где $x_{i j}^{\prime}$ - нормированное среднее за 2015-2019 гг. значение $j$-й характеристики $i$-го штата; $x_{i j}$ - среднее за 2015-2019 гг. значение $j$-го показателя по $i$-му штату США.

С целью выявления корреляционной зависимости между индексами, представленными в официальной американской статистике, раскрывающей в основном ИА РИС штатов США, с одной стороны, и самостоятельно рассчитанными интегральными показателями уровня ИП этих же объектов исследования с другой стороны, проводится расчет ранговой ${ }^{4}$ и линейной ${ }^{5}$ корреляции между ними.

Третьим, заключительным шагом выполняется типологическая группировка штатов США, РИС которых объединяются на основе статистической общности взаимодействия показателей ИП и ИА, приведенных как в форме соответствующих индексов, характеризующих ИА (получены автором в готовом виде из официальных источников), так и в виде интегральных показателей, характеризующих уровень ИП для каждого штата (рассчитаны самостоятельно). Данная группировка призвана:

- во-первых, подтвердить либо опровергнуть гипотезу о неоднородности и неравномерности инновационного развития в пространстве Соединенных Штатов, сложившихся под влиянием (позитивном или негативном) процессов, вызванных этой дифференциацией, и отраженных с помощью соответствующих индексов и интегральных показателей;

- во-вторых, выявить конкретные типы РИС штатов США в разрезе их ИА и уровня ИП посредством проверки имеющихся значений индексов и полученных значений интегрального показателя на соответствие эмпирического распределения одному из теоретических законов: нормальному или логарифмически нормальному (логнормальному). При этом разноуровневые значения указанных индексов и интегрального показателя приводятся к сопоставимым случайным величинам в логнормальном распределении ${ }^{6}$. 


\section{Результаты и обсуждение}

На основе используемого статистического, теоретико-методологического и методического аппарата взятые из источников официальной американской статистики интересующие нас индексы и рассчитанные интегральные показатели по всем штатам и округу Колумбия, относимым по классификации Бюро цензов США к соответствующим субрегионам (статистико-экономическим районам) и обладающим собственными РИС, сведены в таблицу 1.
Анализ данных таблицы и расчет коэффициентов ранговой и линейной корреляции за период 2015-2019 гг. убедительно указывают:

- во-первых, как на высокую корреляционную связь между показателями, характеризующими ИА и уровень ИП в РИС штатов США, - официальных индексов и рассчитанного интегрального показателя, так и на чрезвычайно высокую тесноту взаимосвязи непосредственно между уровнем сформированного и используемого ИП и ИА РИС в пространстве США. Во всех

Показатели, характеризующие уровень инновационного потенциала (ИП) и инновационной активности (ИА) в региональных инновационных системах (РИС) штатов США в среднем за период 2015-2019 гг.

\begin{tabular}{|c|c|c|c|c|c|}
\hline \multirow{2}{*}{\multicolumn{2}{|c|}{ РИС штатов в пространстве субрегионов }} & \multicolumn{4}{|c|}{$\begin{array}{c}\text { Индексы ИА, } \\
\text { интегральные показатели уровня ИП }\end{array}$} \\
\hline & & \multicolumn{2}{|c|}{ Рейтинги РИР } & \multirow[b]{2}{*}{$H D I$} & \multirow[b]{2}{*}{$I P_{i}$} \\
\hline & & $P I I$ & SNEI & & \\
\hline 1 & 2 & 3 & 4 & 5 & 6 \\
\hline \multirow[t]{7}{*}{ Новая Англия } & Вермонт & 53,27 & 54,78 & 4,73 & 0,2729 \\
\hline & Коннектикут & 68,53 & 71,42 & 5,47 & 0,5847 \\
\hline & Массачусетс & 77,38 & 83,75 & 5,58 & 0,6332 \\
\hline & Мэн & 52,44 & 53,24 & 4,67 & 0,2826 \\
\hline & Нью-Гэмпшир & 72,37 & 76,38 & 5,48 & 0,5783 \\
\hline & Род-Айленд & 67,24 & 70,21 & 5,36 & 0,5528 \\
\hline & В среднем по субрегиону & 65,21 & 68,30 & 5,26 & 0,4841 \\
\hline \multirow{4}{*}{$\begin{array}{c}\text { Среднеатлан- } \\
\text { тические } \\
\text { штаты }\end{array}$} & Нью-Джерси & 74,48 & 78,05 & 5,47 & 0,6018 \\
\hline & Нью-Йорк & 80,74 & 86,41 & 5,82 & 0,6292 \\
\hline & Пенсильвания & 72,16 & 76,34 & 5,44 & 0,5785 \\
\hline & В среднем по субрегиону & 75,79 & 80,27 & 5,58 & 0,6011 \\
\hline \multirow{6}{*}{$\begin{array}{c}\text { Северо- } \\
\text { восточный } \\
\text { центр }\end{array}$} & Висконсин & 49,27 & 51,37 & 4,23 & 0,2683 \\
\hline & Иллинойс & 55,87 & 58,03 & 4,52 & 0,3410 \\
\hline & Индиана & 63,22 & 67,15 & 4,74 & 0,4997 \\
\hline & Мичиган & 56,83 & 58,32 & 4,46 & 0,3385 \\
\hline & Огайо & 64,49 & 68,48 & 4,70 & 0,5104 \\
\hline & В среднем по субрегиону & 57,93 & 60,67 & 4,53 & 0,3916 \\
\hline \multirow{8}{*}{$\begin{array}{c}\text { Северо- } \\
\text { западный } \\
\text { центр }\end{array}$} & Айова & 57,46 & 60,12 & 4,63 & 0,3248 \\
\hline & Канзас & 52,20 & 54,88 & 4,59 & 0,2881 \\
\hline & Миннесота & 49,24 & 53,26 & 4,25 & 0,2872 \\
\hline & Миссури & 65,41 & 69,33 & 4,78 & 0,5293 \\
\hline & Небраска & 33,73 & 35,62 & 3,43 & 0,2183 \\
\hline & Северная Дакота & 27,58 & 29,25 & 2,82 & 0,1064 \\
\hline & Южная Дакота & 26,63 & 28,42 & 2,73 & 0,1022 \\
\hline & В среднем по субрегиону & 44,61 & 47,27 & 3,89 & 0,2652 \\
\hline \multirow{5}{*}{$\begin{array}{c}\text { Южноатлан- } \\
\text { тические } \\
\text { штаты }\end{array}$} & Виргиния & 36,88 & 38,25 & 2,92 & 0,2487 \\
\hline & Делавэр & 49,18 & 51,28 & 4,33 & 0,3418 \\
\hline & Джорджия & 41,05 & 43,18 & 3,77 & 0,2920 \\
\hline & Западная Виргиния & 52,23 & 54,32 & 4,93 & 0,3184 \\
\hline & Мэриленд & 71,37 & 76,11 & 6,46 & 0,5822 \\
\hline
\end{tabular}

Примечание. Составлено и рассчитано на основе индексных и абсолютных данных официальной американской статистики, приведенной в списке литературы. 
B.Н. Минат. Пространственная неоднородность инновационной деятельности США

Окончание таблицы 1

\begin{tabular}{|c|c|c|c|c|c|c|}
\hline \multirow[t]{6}{*}{1} & \multirow{2}{*}{\multicolumn{2}{|c|}{$\begin{array}{c}2 \\
\text { Северная Каролина }\end{array}$}} & 3 & 4 & 5 & 6 \\
\hline & & & 65,28 & 68,33 & 6,11 & 0,4041 \\
\hline & \multicolumn{2}{|c|}{ Флорида } & 68,92 & 70,88 & 6,37 & 0,4872 \\
\hline & \multicolumn{2}{|c|}{ Южная Каролина } & 60,02 & 64,24 & 5,65 & 0,3982 \\
\hline & \multicolumn{2}{|c|}{ Округ Колумбия } & 82,84 & 85,60 & 7,39 & 0,6529 \\
\hline & \multicolumn{2}{|c|}{ В среднем по субрегиону } & 58,64 & 61,35 & 5,33 & 0,4139 \\
\hline \multirow{5}{*}{$\begin{array}{c}\text { Юго- } \\
\text { восточный } \\
\text { центр }\end{array}$} & \multicolumn{2}{|c|}{ Алабама } & 33,17 & 36,04 & 2,64 & 0,2272 \\
\hline & \multicolumn{2}{|c|}{ Кентукки } & 35,27 & 39,30 & 2,99 & 0,2540 \\
\hline & \multicolumn{2}{|c|}{ Миссисипи } & 49,85 & 56,13 & 5,12 & 0,3679 \\
\hline & \multicolumn{2}{|c|}{ Теннесси } & 41,23 & 46,27 & 4,28 & 0,2846 \\
\hline & \multicolumn{2}{|c|}{ В среднем по субрегиону } & 39,88 & 44,44 & 3,76 & 0,2834 \\
\hline \multirow{5}{*}{$\begin{array}{c}\text { Юго- } \\
\text { западный } \\
\text { центр }\end{array}$} & \multicolumn{2}{|c|}{ Арканзас } & 37,50 & 41,83 & 2,68 & 0,2887 \\
\hline & \multicolumn{2}{|c|}{ Луизиана } & 50,36 & 54,33 & 4,37 & 0,3248 \\
\hline & \multicolumn{2}{|c|}{ Оклахома } & 35,63 & 38,06 & 2,28 & 0,2253 \\
\hline & \multicolumn{2}{|c|}{ Texac } & 70,14 & 74,36 & 7,18 & 0,5875 \\
\hline & \multicolumn{2}{|c|}{ В среднем по субрегиону } & 48,41 & 52,15 & 4,13 & 0,3566 \\
\hline \multirow{9}{*}{$\begin{array}{l}\text { Горные } \\
\text { штаты }\end{array}$} & \multicolumn{2}{|c|}{ Айдахо } & 32,26 & 34,51 & 3,18 & 0,2104 \\
\hline & \multicolumn{2}{|c|}{ Аризона } & 41,83 & 44,04 & 3,77 & 0,2542 \\
\hline & \multicolumn{2}{|c|}{ Вайоминг } & 24,67 & 25,83 & 2,64 & 0,1004 \\
\hline & \multicolumn{2}{|c|}{ Колорадо } & 55,27 & 57,14 & 4,63 & 0,3425 \\
\hline & \multicolumn{2}{|c|}{ Монтана } & 22,34 & 24,11 & 2,28 & 0,1012 \\
\hline & \multicolumn{2}{|c|}{ Невада } & 64,32 & 66,88 & 5,24 & 0,4912 \\
\hline & \multicolumn{2}{|c|}{ Нью-Мексико } & 68,85 & 69,36 & 5,38 & 0,5188 \\
\hline & \multicolumn{2}{|c|}{ Юта } & 37,28 & 39,47 & 3,31 & 0,2873 \\
\hline & \multicolumn{2}{|c|}{ В среднем по субрегиону } & 43,35 & 45,17 & 3,80 & 0,2883 \\
\hline \multirow{7}{*}{$\begin{array}{l}\text { Тихоокеан- } \\
\text { ские штаты }\end{array}$} & Кал & форния & 94,35 & 96,93 & 6,94 & 0,6892 \\
\hline & Ope & & 64,19 & 65,81 & 4,21 & 0,3937 \\
\hline & Baш & ІНГтон & 68,48 & 68,74 & 4,74 & 0,4228 \\
\hline & Аля & & 26,05 & 26,77 & 2,46 & 0,1190 \\
\hline & Гав & йские острова (Гавайи) & 32,76 & 32,93 & 3,62 & 0,2724 \\
\hline & & по всему субрегиону & 57,17 & 58,24 & 4,39 & 0,3794 \\
\hline & 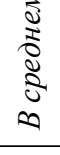 & $\begin{array}{l}\text { по основной } \\
\text { континентальной части } \\
\text { субрегиона (без Аляски и } \\
\text { Гавайских островов) }\end{array}$ & 75,67 & 77,16 & 5,30 & 0,5019 \\
\hline Ранговая корн & Іяци & с колонкой 6 & 0,81 & 0,80 & 0,75 & - \\
\hline Линейная кор & ЛЯци & I с колонкой 6 & 0,78 & 0,76 & 0,70 & - \\
\hline
\end{tabular}

случаях выявляется высокая корреляционная зависимость;

- во-вторых, на наличие четких (и при этом многоуровневых) центр-периферийных тенденций в развитии РИС штатов США. На первом уровне - между субрегионами США, на втором уровне - в пределах каждого отдельно взятого субрегиона, где ярко выражены РИС конкретных штатов, обладающих наиболее высокими показателями развития ИП и ИА (составляющие геоэкономический «центр»), и штаты с менее развитыми РИС по интересующим нас показателям (относимые к «полупериферии» и «пе- риферии» пространственного развития инновационной деятельности).

Представленные положения указывают на интеграционную пространственную взаимосвязь на всех уровнях организации и функционирования РИС штатов и более крупных образований НИС в пределах Юга США за счет не просто количественной оценки ИП, а посредством различий в качественных характеристиках ИА.

Углубить и конкретизировать представление о диалектически едином процессе интеграции и дифференциации инновационногопространства США позволяет типология РИС штатов страны, приведенная в таблице 2. 
Типология региональных инновационных систем (РИС) штатов США на основе логнормального распределения по индексам инновационной активности (ИА) и интегральному показателю уровня инновационного потенциала (ИП) средних значений за период 2015-2019 гг.

\begin{tabular}{|c|c|c|c|c|c|c|}
\hline \multicolumn{3}{|c|}{ РИС штатов каждого типа } & \multicolumn{4}{|c|}{$\begin{array}{l}\text { Критические точки перехода типов, выделенных } \\
\text { на основе логнормального распределения по: }\end{array}$} \\
\hline тип & характеристика & типичные штаты & $P I I$ & SNEI & $H D I$ & $I P_{i}$ \\
\hline I & $\begin{array}{l}\text { Низкий уровень } \\
\text { ИП и ИА }\end{array}$ & $\begin{array}{l}\text { Сев. Дакота, } \\
\text { Юж. Дакота, } \\
\text { Вайоминг, } \\
\text { Монтана, } \\
\text { Аляска }\end{array}$ & $\begin{array}{c}(-\infty \\
-2,112]\end{array}$ & $\begin{array}{c}(-\infty \\
-2,174]\end{array}$ & $\begin{array}{c}(-\infty ; \\
-2,002]\end{array}$ & $\begin{array}{c}(-\infty \\
-2,086]\end{array}$ \\
\hline II & $\begin{array}{l}\text { Уровни ИП и ИА } \\
\text { ниже среднего }\end{array}$ & $\begin{array}{l}\text { Небраска, } \\
\text { Алабама, } \\
\text { Оклахома, } \\
\text { Айдахо }\end{array}$ & $\begin{array}{l}(-2,112 \\
-1,932]\end{array}$ & $\begin{array}{l}(-2,174 \\
-1,963]\end{array}$ & $\begin{array}{l}(-2,002 ; \\
-1,833]\end{array}$ & $\begin{array}{l}(-2,086 ; \\
-1,988]\end{array}$ \\
\hline III & $\begin{array}{l}\text { Уровень ИП ниже } \\
\text { среднего в соче- } \\
\text { тании со средним } \\
\text { значением ИА }\end{array}$ & $\begin{array}{l}\text { Виргиния, } \\
\text { Кентукки, } \\
\text { Арканзас, } \\
\text { Аризона, } \\
\text { Юта, } \\
\text { Гавайи }\end{array}$ & $\begin{array}{l}(-1,932 \\
-1,764]\end{array}$ & $\begin{array}{r}(-1,963 \\
-1,779]\end{array}$ & $\begin{array}{l}(-1,833 \\
-1,648]\end{array}$ & $\begin{array}{l}(-1,988 \\
-1,794]\end{array}$ \\
\hline IV & $\begin{array}{l}\text { Средний уровень } \\
\text { ИП и ИА }\end{array}$ & $\begin{array}{l}\text { Висконсин, } \\
\text { Миннесота, } \\
\text { Джорджия, } \\
\text { Теннесси }\end{array}$ & $\begin{array}{l}(-1,764 \\
-1,581]\end{array}$ & $\begin{array}{l}(-1,779 \\
-1,608]\end{array}$ & $\begin{array}{l}(-1,648 \\
-1,512]\end{array}$ & $\begin{array}{l}-1,794 \\
-1,503]\end{array}$ \\
\hline V & $\begin{array}{l}\text { Среднее значение } \\
\text { ИА в сочетании с } \\
\text { уровнем ИП вы- } \\
\text { ше среднего }\end{array}$ & $\begin{array}{l}\text { Вермонт, } \\
\text { Мэн, } \\
\text { Канзас }\end{array}$ & $\begin{array}{l}(-1,581 \\
-1,376]\end{array}$ & $\begin{array}{l}(-1,608 \\
-1,461]\end{array}$ & $\begin{array}{l}(-1,512 ; \\
-1,333]\end{array}$ & $\begin{array}{l}(-1,503 ; \\
-1,399]\end{array}$ \\
\hline VI & $\begin{array}{l}\text { Значения ИП и } \\
\text { ИА выше сред- } \\
\text { него }\end{array}$ & $\begin{array}{c}\text { Иллинойс, } \\
\text { Мичиган, } \\
\text { Айова, } \\
\text { Делавэр, } \\
\text { Зап. Виргиния, } \\
\text { Юж. Каролина, } \\
\text { Миссисипи, } \\
\text { Луизиана, } \\
\text { Колорадо }\end{array}$ & $\begin{array}{l}(-1,376 \\
-1,202]\end{array}$ & $\begin{array}{l}(-1,461 \\
-1,229]\end{array}$ & $\begin{array}{l}(-1,333 \\
-1,161]\end{array}$ & $\begin{array}{l}(-1,399 ; \\
-1,223]\end{array}$ \\
\hline VII & $\begin{array}{l}\text { Сочетание зна- } \\
\text { чений ИА выше } \\
\text { среднего с высо- } \\
\text { ким значением } \\
\text { ИП }\end{array}$ & $\begin{array}{c}\text { Индиана, } \\
\text { Огайо, } \\
\text { Миссури, } \\
\text { Сев. Каролина, } \\
\text { Флорида, } \\
\text { Невада, } \\
\text { Нью-Мексико, } \\
\text { Орегон, } \\
\text { Вашингтон } \\
\end{array}$ & $\begin{array}{l}(-1,202 \\
-1,088]\end{array}$ & $\begin{array}{l}(-1,229 \\
-1,096]\end{array}$ & $\begin{array}{l}(-1,161 \\
-1,071]\end{array}$ & $\begin{array}{l}(-1,223 ; \\
-1,049]\end{array}$ \\
\hline VIII & $\begin{array}{l}\text { Высокий уро- } \\
\text { вень ИП и ИА }\end{array}$ & $\begin{array}{c}\text { Коннектикут, } \\
\text { Массачусетс, } \\
\text { Нью-Гэмпшир, } \\
\text { Род-Айленд, } \\
\text { Нью-Джерси, } \\
\text { Нью-Йорк, } \\
\text { Пенсильвания, } \\
\text { Мэриленд, } \\
\text { Окр. Колумбия, } \\
\text { Техас, } \\
\text { Калифорния } \\
\end{array}$ & $\begin{array}{c}(-1,088 \\
0]\end{array}$ & $(-1,096 ; 0]$ & $\begin{array}{c}(-1,071 \\
0]\end{array}$ & $\begin{array}{c}(-1,049 ; \\
0]\end{array}$ \\
\hline
\end{tabular}

Примечание. Рассчитано на основе индексных и абсолютных данных официальной американской статистики, приведенной в списке литературы. 
Логонормальное распределение РИС штатов США по сочетанию приведенных показателей ИА и уровня ИП, разграничиваемое на основе расчета критических точек качественного перехода (переходов) состояний, позволяет выделить 8 типов РИС соответствующих территориально-структурных образований. Некоторые из них, где уровень ИП и ИА прямо соответствуют по характеристикам (например, значение ИА и уровня ИП выше среднего), можно условно отнести к основным типам (I, II, IV, VI, VIII), а остальные, где наблюдается разноуровневое сочетание ИП и ИА, - к переходным типам (III, V, VII).

Полученное типологическое разнообразие, основанное на многовариантном сочетании показателей уровня ИП и ИА РИС штатов США, отражает сложные тенденции пространственного развития инновационной деятельности в этом макрорегионе США, проявляющиеся следующим образом.

Во-первых, в групповом преобладании типов РИС штатов с высокими показателями ИП и ИА и сочетанием высокого значения ИП с ИА выше среднего (типы VIII и VII) - 20 из 51 (39 \%) исследуемых территориальных образований, относимых нами к «центру» инновационного развития США. Указанный «геоинновационный центр» США составляют субрегионы Новая Англия, Среднеатлантические штаты (причем на 100 \%), Тихоокеанские штаты (при условии расчета их основной континентальной части). Таким образом, в пространстве США центральное положение инновационных «локомативов» занимают субрегионы, географически расположенные на противоположных побережьях страны, увязывая на себя субрегионы полупериферийных типов инновационного развития.

Во-вторых, обозначенные выше как полупериферийные субрегионы (Северо-восточный центр, Южноатлантические штаты), обладая некоторыми РИС штатов VIII (Мэриленд, округ Колумбия) и VII типов (Северная Каролина, Флорида), преимущественно включают РИС штатов VI типа. Общее для полупериферийных субрегионов состоит в том, что РИС составляющих их штатов результативно и эффективно проявляют ИА, полноценно используя имеющийся ИП.
В-третьих, исходя из характеристики РИС штатов V типа (две из которых расположены в пределах Новой Англии, относимой к «центру», а РИС штата Канзас - к «периферии»), можно считать ИА, проявляемую в РИС этих штатов, недостаточной в сравнении с уровнем имеющегося ИП. Следовательно, будущее инновационного развития, вполне возможно, имеет перспективы к росту именно здесь. По этой причине РИС трех штатов указанного типа трудно персонифицировать в рамках центр-периферийной концепции.

В-четвертых, многообразием отличается группировка периферийных в инновационном развитии штатов США, включающая субрегионы Северо-западный центр, Юго-восточный центр, Юго-западный центр и Горные штаты. В периферийном инновационном пространстве располагаются РИС двух из четыpex штатов IV группы (Миннесота, Теннесси), отличающиеся средними показателями ИА и уровня ИП, но ее основы составляют РИС штатов I-III групп, причем почти стопроцентно относимых к субрегионам инновационной «периферии» (за исключением Висконсина, Гавайских островов и Аляски). Самую многочисленную группу составляют штаты, РИС которых выделен в переходный III тип, характеризующийся сочетанием средних показателей ИА с уровнем ИП ниже среднего. Несомненно, превышение показателей ИА над уровнем ИП связано с тесными взаимоотношениями элементов РИС этих штатов (как в сфере НИОКР, так и по линии агентовноваторов и организаций-новаторов) с аналогичными системами соседних и близко расположенных штатов, отличающихся высокоразвитой инновационной деятельностью, что как раз и подчеркивает их явную «перефирийность» в ориентации инновационного развития.

\section{Выводы}

Подводя общий итог, отметим, что проведенный анализ и предложенная оценка уровня ИП и ИА как сочетания экономических свойств (факторов) конкретных РИС позволили провести типологическую группировку последних, а также обосновать ряд тенденций пространственной неоднородности инновационной деятельности, осуществляемой 
РИС штатов Юга США, и использования данного опыта.

Первая тенденщия состоит в широком пространственном многообразии РИС штатов США, что определяет не только неоднородный геоэкономический «рисунок» инновационной деятельности как на уровне субрегионов (рассмотренных подробно), так и внутри каждого из них по центр-периферийному принципу, но и указывает на вариативность сочетаний уровня ИП и ИА, характерных для различных объектов настоящего исследования. Данный факт указывает на диалектическое единство инновационной деятельности как пространственного экономического фактора развития целостных территорий мезоуровня.

Вторая тенденщия, связанная с методическим подходом к исследованию ИП и ИА РИС штатов США, раскрывается в переходе количественных характеристик исследуемых объектов на качественный уровень, отражаемый в виде как соответствующих индексов, используемых в американской науке и практике, так и непосредственно рассчитанных автором интегральных показателей, имеющих высокую корреляцию с ними. Подобный подход, на наш взгляд, небезынтересен для использования в эмпирических исследованиях ИП и ИА, а также иных характеристик / факторов инновационной деятельности других пространственных образований, имеющих отношение в том числе и к России, где указанная выше дифференциация регионов по показателям «инновационности» еще более рельефна и неоднородна, чем в США.

Отмеченные тенденции подтверждают гипотезу о неоднородности и неравномерности развития экономики территорий страны под влиянием процессов, вызванных дифференциацией пространственных структур, в рамках которых осуществляется инновационная деятельность.

\section{ПРИМЕЧАНИЯ}

${ }^{1}$ Американский PII, разрабатываемый при содействии Министерства торговли США для американских штатов и округов, состоит из четырех блоков: человеческий капитал (human capital), экономическая динамика (economic dynamics), произво- дительность и занятость (productivity and employment), благосостояние (economic well-being).

${ }^{2}$ Результаты трансформации экономики региона по рейтингу SNEI оцениваются по следующим направлениям: работники наукоемкого сектора экономики и высококвалифицированные работники (доля и прирост); степень глобализации / открытости экономики; экономическая динамика (показатели ведения бизнеса); цифровая экономика (степень развития сектора ИКТ), инновационный потенциал как набор разных параметров развития инновационной сферы (включая условия и результаты инновационной деятельности).

${ }^{3} \mathrm{HDI}$ ежегодно рассчитывается для измерения и сравнения уровня и ожидаемой продолжительности жизни, здоровья, образованности и иных характеристик человеческого капитала (потенциала) конкретной территории США.

${ }^{4}$ Для этого используется коэффициент ранговой корреляции Спирмена и устанавливается теснота связи по шкале Чеддока: 0,3 или меньше - слабая связь, $0,4-0,7$ - средняя, 0,7-0,9- высокая теснота, 0,9-1 - крайне высокая.

5 Линейный коэффициент корреляции Пирсона показывает тесноту линейной взаимосвязи и изменяется в диапазоне от -1 до $1 ;-1$ означает полную (функциональную) линейную обратную взаимосвязь; 1 - полную (функциональную) линейную положительную взаимосвязь; 0 - отсутствие линейной корреляции, но не обязательно взаимосвязи.

${ }^{6}$ Алгоритм типологической группировки территориальных образований (регионов) изложен и апробирован в работе: [Зайков, 2019, с. 141-142, 145-148].

\section{СПИСОК ЛИТЕРАТУРЫ}

Антоненко, И. В. Национальная инновационная система как основа формирования и реализации инновационного потенциала региональной экономики / И. В. Антоненко // Вестник Волгоградского государственного университета. Экономика. - 2019. - Т. 21, № 4. - С. 99-109. DOI: https://doi.org/10.15688/ek.jvolsu.2019.4.10.

Баринова, В. А. Некоторые методологические подходы к рейтингованию регионов по результатам инновационной деятельности / В. А. Баринова, С. П. Земцов, Р. И. Семенова. - М. : РАНХиГС при Президенте РФ, 2017. - 220 с.

Бухарова, Е. М. Опыт США и ФРГ в развитии региональных инновационных систем / Е. М. Бухарова // Инновации. - 2013. - № 1 (171). C. $68-75$.

Зайков, К. А. К вопросу оценки уровня инновационного потенциала субъектов Российской 
Федерации / К. А. Зайков // Вестник НГУЭУ. 2019. - № 1. - С. 134-151.

Лапаев, С. П. Опыт развитых стран по формированию инновационной модели развития регионов // Вестник Оренбургского государственного университета. - 2012. - № 8 (144). - С. 123-132.

Минат, В. Н. Государственная региональная политика и развитие региональных инновационных систем в США / В. Н. Минат // Федерализм. -2020а. - Т. 25, № 4. - С. 173-188. - DOI: 10.21686/2073-1051-2020-4-173-188.

Минат, В. Н. Особенности функционирования региональных инновационных систем в штатах Ceвера США / В. Н. Минат // Вестник НГУЭУ. 2020б. -№3.-C. 198-213.-DOI: 10.34020/20736495-2020-3-198-213.

Минат, В.Н. Типы территориальных форм национальной инновационной системы США и их концентрация в городских агломерациях / В. Н. Минат // Инновации. - 2020в. - № 5 (259). - С. 68-80. DOI: $10.26310 / 2071-3010.2020 .259 .5 .010$

Монахов, И. А. Индикаторы и показатели инновационной активности стран и территориальных образований: зарубежный опыт / И. А. Монахов // Вестник ТвГУ. Серия: Экономика и управление. - 2013. - № 3. C. 35-49.

Abel, Z.T. Innovation potential of individual states of the Midwest / Z.T. Abel // Journal of Economic Perspectives. - 2017. - Vol. 31. No. 1. - P. 177-208.

Carbelli, B. Innovation Activity. Regional experience of economic development / B. Carbelli // The American Economic Review. - 2018. - Vol. 108.No. 6. - P. 1288-1321.

Innovation in American Regions. - Electronic text data. Mode of access: http://www.statsamerica. org/innovation/index.html (date of access: 20.12.2020). - Title from screen.

List of U.S. states by American Human Development Index. - Electronic text data. - Mode of access: https://ru.qaz.wiki/wiki/List_of_U.S._states_by_ American_Human_Development Index (date of access: 20.12.2020). - Title from screen.

Porter, M. E. Determinants of National Innovation Capacities / M. E. Porter, S. Stern // Research Policy. - 2002. - № 31 (6). - P. 899-933. Electronic text data. - Mode of access: https:// econpapers.repec.org/article/eeerespol/v (date of access: 05.01.2021). - Title from screen.

State New Economy Index. Benchmarking Economic Transformation in the States. Information Technology and Innovation Foundation (ITIF). - Electronic text data. - Mode of access: http://www2.itif.org/state-new-economy-index (date of access: 20.12.2020). - Title from screen.

\section{REFERENCES}

Antonenko I.V. Nacional'naya innovacionnaya sistema kak osnova formirovaniya i realizacii innovacionnogo potenciala regional'noj ekonomiki [National Innovation System as a Basis for Forming and Implementing the Regional Economy Innovation Capacity]. Vestnik Volgogradskogo gosudarstvennogo universiteta. Ekonomika [Journal of Volgograd State University. Economics], 2019, vol. 21, no. 4,pp. 99-109. DOI: https://doi.org/ 10.15688/ek.jvolsu.2019.4.10.

Barinova V.A., Zemcov S.P., Semenova R.I. Nekotorye metodologicheskie podhody $k$ rejtingovaniyu regionov po rezul'tatam innovacionnoj deyatel'nosti [Some Methodological Approaches to the Ranking of Regions Based on the Results of Innovation Activities]. Moscow, RANHiGS pri Prezidente RF, 2017.220 p.

Buharova E.M. Opyt SShA i FRG v razvitii regional'nyh innovacionnyh system [Experience of the USA and Germany in the Development of Regional Innovation Systems]. Innovacii [Innovations], 2013, no. 1 (171), pp. 68-75.

Zaykov K.A. K voprosu ocenki urovnya innovacionnogo potenciala subyektov Rossijskoj Federacii [To the Question of the Assessment of the Russian Federation Regions Innovative Potential Level]. Vestnik NGUEU [Vestnik NSUEM], 2019, no. 1, pp. 134-151.

Lapaev S.P. Opyt razvityh stran po formirovaniyu innovacionnoj modeli razvitiya regionov [The Experience of Developed Countries on the Formation of the Innovative Model of Development of the Regions]. Vestnik Orenburgskogo gosudarstvennogo universiteta [Vestnik Orenburg State University], 2012, no. 8 (144), pp. 123-132.

Minat V.N. Gosudarstvennaya regional'naya politika i razvitie regional'nyh innovacionnyh sistem $\mathrm{v}$ SShA [Public Regional Policy and the Development of Regional Innovation Systems in the USA]. Federalizm [Federalism], 2020a, vol. 25, no. 4, pp. 173-188. DOI: 10.21686/20731051-2020-4-173-188.

Minat V.N. Osobennosti funkcionirovaniya regional'nyh innovacionnyh sistem v shtatah Severa SShA [Features of Regional Innovation Systems Function in the Northern States of the USA]. Vestnik NGUEU[Vestnik NSUEM], 2020b, no. 3, pp. 198213.DOI: 10.34020/2073-6495-2020-3-198-213.

Minat V.N. Tipy territorial'nyh form nacional'noj innovacionnoj sistemy SShA i ih koncentraciya v gorodskih aglomeraciyah [Types of Territorial Forms National Innovation System of the USA and Their Concentration in Urban Agglomerations]. 
Innovacii [Innovations], 2020v, no. 5 (259), pp. 68-80.DOI: 10.26310/2071-3010.2020.259.5.010.

Monahov I.A. Indikatory i pokazateli innovacionnoj aktivnosti stran i territorial'nyh obrazovanij: zarubezhnyj opyt [Indicators and Indices of Innovation Activity of Countries and Territories: International Experience]. Vestnik TvGU. Seriya: Ekonomika i upravlenie [Herald of Tver State University. Series: Ekonomika I Upravlenie], 2013, no. 3, pp. 35-49.

Abel Z.T. Innovation Potential of Individual States of the Midwest. Journal of Economic Perspectives, 2017, vol. 31, no. 1, pp. 177-208.

Carbelli B. Innovation Activity. Regional Experience of Economic Development. The American Economic Review, 2018, vol. 108, no. 6, pp. 1288-1321.
Innovation in American Regions. URL: http://www. statsamerica.org/innovation/index.html (accessed 20 December 2020).

List of U.S. States by American Human Development Index. URL: https://ru.qaz.wiki/wiki/List_of U.S._states_by_American_Human_Development Index (accessed 20 December 2020).

Porter M.E., Stern S. Determinants of National Innovation Capacities. Research Policy, 2002, no. 31 (6), pp. 899-933. URL: https://econpapers.repec.org/ article/eeerespol/v (accessed 5 January 2021).

State New Economy Index. Benchmarking Economic Transformation in the States. Information Technology and Innovation Foundation (ITIF). URL: http://www2.itif.org/state-new-economyindex (accessed 20 December 2020).

\section{Information About the Author}

Valerij N. Minat, Candidate of Sciences (Geography), Associate Professor, Department of Economics and Management, Ryazan State Agrotechnological University named after P.A. Kostychev, Kostycheva St, 1, 390044 Ryazan, Russian Federation, minat.valera@yandex.ru, https://orcid.org/0000-0002-8787-4274

\section{Информация об авторе}

Валерий Николаевич Минат, кандидат географических наук, доцент кафедры экономики и менеджмента, Рязанский государственный агротехнологический университет им. П.А. Костычева, ул. Костычева, 1, 390044 г. Рязань, Российская Федерация, minat.valera@yandex.ru, https://orcid.org/0000-0002-8787-4274 